\title{
Clinical prediction rules for failed nonoperative reduction of intussusception
}

\author{
This article was published in the following Dove Press journal: \\ Therapeutics and Clinical Risk Management \\ 13 September 2016 \\ Number of times this article has been viewed
}

\author{
Jiraporn Khorana' \\ Jayanton Patumanond ${ }^{2}$ \\ Nuthapong Ukarapol ${ }^{3}$ \\ Mongkol Laohapensang ${ }^{4}$ \\ Pannee Visrutaratna ${ }^{5}$ \\ Jesda Singhavejsakul \\ 'Department of Surgery, Division \\ of Pediatric Surgery, Chiang \\ Mai University Hospital, Chiang \\ Mai, ${ }^{2}$ Center of Excellence in \\ Applied Epidemiology, Thammasat \\ University Hospital, Bangkok, \\ ${ }^{3}$ Department of Pediatrics, Division \\ of Gastroenterology, Chiang Mai \\ University Hospital, Chiang Mai, \\ ${ }^{4}$ Department of Surgery, Division \\ of Pediatric Surgery, Siriraj \\ Hospital, Mahidol University, \\ Bangkok, ${ }^{5}$ Department of Radiology, \\ Chiang Mai University Hospital, \\ Chiang Mai, Thailand
}

Purpose: The nonoperative reduction of intussusception in children can be performed safely if there are no contraindications. Many risk factors associated with failed reduction were defined. The aim of this study was to develop a scoring system for predicting the failure of nonoperative reduction using various determinants.

Patients and methods: The data were collected from Chiang Mai University Hospital and Siriraj Hospital from January 2006 to December 2012. Inclusion criteria consisted of patients with intussusception aged $0-15$ years with no contraindications for nonoperative reduction. The clinical prediction rules were developed using significant risk factors from the multivariable analysis.

Results: A total of 170 patients with intussusception were included in the study. In the final analysis model, 154 patients were used for identifying the significant risk factors of failure of reduction. Ten factors clustering by the age of 3 years were identified and used for developing the clinical prediction rules, and the factors were as follows: body weight $<12 \mathrm{~kg}$ (relative risk $[\mathrm{RR}]=1.48, P=0.004)$, duration of symptoms $>48$ hours $(\mathrm{RR}=1.26, P<0.001)$, vomiting (RR $=1.63, P<0.001)$, rectal bleeding $(\mathrm{RR}=1.50, P<0.001)$, abdominal distension $(\mathrm{RR}=1.60$, $P=0.003)$, temperature $>37.8^{\circ} \mathrm{C}(\mathrm{RR}=1.51, P<0.001)$, palpable mass $(\mathrm{RR}=1.26, P<0.001)$, location of mass (left over right side $\mathrm{RR}=1.48, P<0.001$ ), ultrasound showed poor prognostic signs $(\mathrm{RR}=1.35, P<0.001$ ), and the method of reduction (hydrostatic over pneumatic, $\mathrm{RR}=1.34$, $P=0.023$ ). Prediction scores ranged from 0 to 16. A high-risk group (scores 12-16) predicted a greater chance of reduction failure (likelihood ratio of positive $[\mathrm{LR}+]=18.22, P<0.001$ ). A low-risk group (score $0-11$ ) predicted a lower chance of reduction failure (LR+ $=0.79$, $P<0.001$ ). The performance of the scoring model was $80.68 \%$ (area under the receiver operating characteristic curve).

Conclusion: This scoring guideline was used to predict the results of nonoperative reduction and forecast the prognosis of the failed reduction. The usefulness of these prediction scores is for informing the parents before the reduction. This scoring system can be used as a guide to promote the possible referral of the cases to tertiary centers with facilities for nonoperative reduction if possible.

Keywords: intussusception, nonoperative reduction, failure rate, clinical prediction rules

\section{Introduction}

Intussusception was a common cause of bowel obstruction and lower gastrointestinal bleeding in infants and children with an incidence of one to four in $2000 .^{1}$ The invagination of one part of the intestine into another distal part causes intussusception. Two of the most common symptoms are vomiting and colicky abdominal pain. In addition, the two most common signs are an abdominal mass and rectal bleeding. ${ }^{1}$ The diagnosis of intussusception can be determined by ultrasound with $100 \%$ accuracy by an experienced
Correspondence: Jesda Singhavejsaku Department of Surgery, Division of Pediatric Surgery, Chiang Mai University Hospital, I I Intavaroros Road, Sriphum, Muang, Chiang Mai 50200, Thailand

Tel +66819929767

Fax +66 53936139

Email pedsurgerycmu@gmail.com (c) (1) (5) 2016 Khorana et al. This work is published and licensed by Dove Medical Press Limited. The full terms of this license are available at https://www.dovepress.com/terms.php (c) ${ }_{\mathrm{BY}} \mathrm{NC}$ and incorporate the Creative Commons Attribution - Non Commercial (unported, v3.0) License (http://creativecommons.org/licenses/by-nc/3.0/). By accessing the work you hereby accept the Terms. Non-commercial uses of the work are permitted without any further permission from Dove Medical Press Limited, provided the work is properly attributed. For permission for commercial use of this work, please see paragraphs 4.2 and 5 of our Terms (https://www.dovepress.com/terms.php). 
examiner and according to the clinical case definition for the diagnosis of acute intussusception proposed by the Brighton Collaboration Intussusception Working Group. ${ }^{2}$

Currently, treatment modalities for intussusception comprise nonsurgical and surgical treatment. The attempt of nonsurgical treatment is performed if no contraindications are present, which include signs of perforation (peritonitis, pneumoperitoneum in a plain abdominal X-ray) and a hemodynamically unstable patient in spite of adequate resuscitation. Surgical treatment is performed when nonsurgical treatment is contraindicated or has failed. The nonsurgical reduction procedure can be performed by hydrostatic or pneumatic pressure enema under ultrasound or fluoroscopy.

The diagnosis and treatment methods vary around the world depending on resources and equipment. In 2013, Jiang et $\mathrm{al}^{3}$ reviewed global intussusception. The findings indicated that $95 \%-100 \%$ of the cases were diagnosed by a radiographic study (air contrast enema, ultrasound, or computed tomography) in all the World Health Organization regions except Africa where $65 \%$ of cases were diagnosed by clinical findings or surgery. The global incidence of treatment with air or barium enema accounted for $66 \%$. In Africa and Central and South America, the primary treatment was surgery. In recent reports of some areas, surgery was still the primary treatment. ${ }^{4}$

The reported success of nonsurgical reduction in the literature ranged from $46 \%$ to $94 \% .{ }^{5}$ Risk factors associated with failed reduction were studied in some series. In 2014, He et $\mathrm{al}^{6}$ reported that initial intussusception was located in the descending colon/rectum with the presence of peritoneal fluid, trapped fluid in the intussusception, and bloody stools as the factors. In 2013, Fallon et $\mathrm{al}^{7}$ described the predictors of abdominal symptoms $>2$ days, age $<1$ year, and multiple ultrasound findings. Our earlier series studied the prognosis indicators for failed reduction and found that body weight $<12 \mathrm{~kg}$, duration of symptoms $>3$ days, vomiting, rectal bleeding, abdominal distension, temperature $>37.8^{\circ} \mathrm{C}$, palpable abdominal mass, location of mass on the left side, ultrasound showing poor prognostic signs, and the method of reduction (hydrostatic over pneumatic) were the factors. ${ }^{8}$

Many factors seem to influence successful or failed reduction. In this study, we aimed to develop a scoring system for predicting the failure of nonsurgical reduction using various determinants that were found in the earlier studies.

\section{Patients and methods}

This retrospective cohort study was approved by the ethics committees of Chiang Mai University (CMU) Hospital and Siriraj (SI) Hospital. Due to the retrospective nature of this study, both committees waived the need for patient consent. This study was the third study in cluster of study series regarding intussusception. The first study reported comparative results of the success rates of hydrostatic and pneumatic reduction. ${ }^{9}$ The second study reported the prognostic indicators of failed operative reduction. ${ }^{8}$ This was the third study that used ten prognostic factors for failed nonsurgical reduction derived from the second study.

\section{Patients}

This was a two institution review. The data were collected from patient charts and electronic medical records of the patients with intussusception (ICD-10 code K56.1) in CMU and SI. The study period was between January 2006 and December 2012. We included the patients who were diagnosed with intussusception from the age of 0 year to 15 years who received nonsurgical reduction as an initial treatment. We excluded patients who had contraindications for nonsurgical reduction at presentation. Absolute contraindications were peritonitis, pneumoperitoneum in abdominal X-ray, and hemodynamic instability. The method of nonsurgical reduction in CMU was all pneumatic reduction under fluoroscopy, whereas the main method of reduction in SI was hydrostatic reduction under fluoroscopy by radiologist. Thus, the method of reduction could be used as one of the predictors.

\section{Predictive variables}

The chart and electronic database reviews collected the data of following ten significant factors: body weight, duration of symptoms, vomiting, rectal bleeding, abdominal distension, temperature, palpable abdominal mass, location of mass, ultrasound showed poor prognostic signs, and the method of reduction. The demographic data such as age and sex were also collected. Poor prognostic signs by ultrasound were a thick peripheral hypoechoic rim, free intraperitoneum fluid, fluid trapped within the intussusception, enlarged lymph node in intussusception, pathologic leading point, and the absence of blood flow in the intussusception, and were counted if one of these signs mentioned was present.

\section{Outcome variables}

The results of the nonsurgical reductions were collected. The patients were divided into two groups: a successful reduction group and a failed reduction group.

\section{Statistical analysis}

The statistical analysis was performed by using commercial statistical software (STATA 11.0; StataCorp LP, College Station, TX, USA). The data were presented in count and 
percentage. The univariable comparative statistics were performed by Fisher's exact test for categorical data and by Student's $t$-test or Mann-Whitney $U$-test for continuous data depending on data distribution. Generalized linear model for exponential risk regression clustering by the age of 3 years (due to the risk for pathologic leading point) was used for multivariable analysis.

Ten significant risk factors were used for the clinical prediction model for failed reduction of intussusception derivation. Numerical factors such as body weight, duration of symptoms, and temperature were divided into two groups. The cutoff points were determined from the values that yielded all statistically significant regression coefficients and the highest area under the receiver operating characteristic (ROC) curve of the logistic regression model.

The regression coefficients of each factor were transformed into item scores. All item scores were added together for a total score. The total scores were used as a predictor for failed nonsurgical reduction of intussusception. The risk level was to categorize total scores into a low-risk group and a high-risk group. The cutoff points for the total scores were determined from the values that yielded the lowest likelihood ratio of positive for failed reduction in the low-risk group and highest likelihood ratio of positive for failed reduction in the high-risk group. The statistical significance level was set as two tailed with a $P$-value of $<0.05$.

\section{Results}

A total of 190 episodes of intussusception were collected from two institutions. Primary surgery at first visit was performed in 20 patients due to contraindications for nonsurgical reduction. According to the retrospective study, some of the missing data were found in 16 records. A total of 154 episodes of intussusception were collected for final prediction model analysis. The median age of the included patients was 9 months (maximum 124 months). There were 114 boys $(67 \%)$ and 56 girls (33\%). The comparative characteristics of 170 patients with intussusception who had successful reductions and failed nonsurgical reductions are shown in Table 1 . The mean weight was significantly lower in the failed group (mean $8.61 \pm 1.98$ in the failed group vs mean $10.15 \pm 3.90$ in the successful group, $P=0.002$ ). Rectal bleeding and abdominal distension were found more in the failed group (54.62\% vs $45.38 \%, P<0.001$, and $61.54 \%$ vs $38.46 \%$, $P<0.001$ respectively). The mean body temperature was slightly higher in the failed group (mean $37.51 \pm 0.68$ in the failed group vs mean $37.12 \pm 0.62$ in the successful group, $P<0.001$ ). Masses were located more on the left side in
Table I Characteristics of children with intussusception with failed $(n=76)$ and successful $(n=94)$ nonsurgical reduction

\begin{tabular}{|c|c|c|c|}
\hline Characteristics & $\begin{array}{l}\text { Failed, } \\
\text { n (\%) }\end{array}$ & $\begin{array}{l}\text { Successful, } \\
\text { n (\%) }\end{array}$ & $P$-value \\
\hline \multicolumn{4}{|l|}{ Demography } \\
\hline Weight (kg) ${ }^{\mathrm{a}}$ & $8.61(1.98)$ & $10.15(3.90)$ & \\
\hline Weight $\leq 12 \mathrm{~kg}$ & $73(49.66)$ & $74(50.34)$ & 0.001 \\
\hline Weight $>12 \mathrm{~kg}$ & $3(13.04)$ & $20(86.96)$ & \\
\hline \multicolumn{4}{|l|}{ Symptoms } \\
\hline $\begin{array}{l}\text { Duration of symptoms } \\
\text { (hours) }^{b}\end{array}$ & $24(24)$ & $24(30)$ & \\
\hline Duration $\leq 48$ hours & $60(42.86)$ & $80(57.14)$ & 0.318 \\
\hline Duration $>48$ hours & $16(53.33)$ & $14(46.67)$ & \\
\hline Vomiting & $71(48.30)$ & $76(5 \mathrm{I} .70)$ & 0.023 \\
\hline Rectal bleeding & $65(54.62)$ & $54(45.38)$ & $<0.001$ \\
\hline Abdominal distension & $48(6 \mid .54)$ & $30(38.46)$ & $<0.001$ \\
\hline \multicolumn{4}{|l|}{ Signs } \\
\hline Temperature $\left({ }^{\circ} \mathrm{C}\right)^{\mathrm{a}}$ & $37.51(0.68)$ & $37.12(0.62)$ & \\
\hline Temperature $\leq 37.8^{\circ} \mathrm{C}$ & $48(36.09)$ & $85(63.91)$ & $<0.001$ \\
\hline Temperature $>37.8^{\circ} \mathrm{C}$ & $28(75.68)$ & $9(24.32)$ & \\
\hline Palpable mass & $55(48.67)$ & $58(5 \mathrm{I} .33)$ & 0.191 \\
\hline \multicolumn{4}{|l|}{ Location } \\
\hline Right side & $43(38.39)$ & $69(6 \mathrm{I} .6 \mathrm{I})$ & 0.020 \\
\hline Left side & $32(58.18)$ & $23(4 I .82)$ & \\
\hline \multicolumn{4}{|l|}{ Investigations } \\
\hline $\begin{array}{l}\text { Ultrasound (poor } \\
\text { prognosis sign) }\end{array}$ & $35(5 \mathrm{I} .47)$ & $33(48.53)$ & 0.330 \\
\hline \multicolumn{4}{|l|}{ Method of reduction } \\
\hline Hydrostatic & $33(55.93)$ & $26(44.07)$ & 0.036 \\
\hline Pneumatic & $43(38.74)$ & $68(61.26)$ & \\
\hline
\end{tabular}

Notes: a Mean (standard deviation). 'Median (interquartile range).

the failed group ( $58.18 \%$ vs $41.82 \%, P=0.020)$. Hydrostatic reduction was also found more frequently in the failed group (55.93\% vs $44.07 \%, P=0.036$ ). The median duration of symptoms, palpable abdominal mass, and ultrasound findings with poor prognostic signs were not significantly different in univariable analysis.

Ten prognostic factors were identified from the earlier studies with statistical differences between the failed and successful reduction groups in multivariable analysis by exponential risk regression, which are shown in Table 2. Risk scoring assignment was performed to forecast the possibility of a failed nonsurgical reduction of intussusception. The regression coefficients were transformed to transform coefficients by dividing with the smallest coefficient in the model which was 0.23 and then rounded up to the nearest integer to be an assigned score. The Item Scoring Scheme is shown in Table 3. The total scores ranged from 0 to 16 .

After using the ten parameters that were transformed into a score, the ROC curve of the failed nonoperative reduction of intussusceptions predicted by risk scoring scheme was performed. The area under the ROC curve that determined 
Table 2 Regression coefficient, RR, and $95 \% \mathrm{Cl}$ of selected risk indicators for failed reduction of intussusceptions derived from generalized linear model

\begin{tabular}{|c|c|c|c|c|}
\hline Risk indicators & Coefficients & $\mathbf{R} \mathbf{R}$ & $95 \% \mathrm{Cl}$ of $\mathbf{R R}$ & $P$-value \\
\hline Weight $\leq 12 \mathrm{~kg}$ & 0.39 & 1.48 & $1.13-1.94$ & 0.004 \\
\hline $\begin{array}{l}\text { Duration of symptoms } \\
>48 \text { hours }\end{array}$ & 0.23 & 1.26 & $1.25-1.26$ & $<0.001$ \\
\hline Vomiting & 0.49 & 1.63 & $1.54-1.73$ & $<0.001$ \\
\hline Rectal bleeding & $0.4 I$ & 1.50 & $1.20-1.89$ & $<0.001$ \\
\hline Abdominal distension & 0.47 & 1.60 & $1.18-2.17$ & 0.003 \\
\hline Temperature $>37.8^{\circ} \mathrm{C}$ & 0.41 & 1.51 & I.47-I.55 & $<0.001$ \\
\hline Palpable mass & 0.23 & 1.26 & $1.24-1.28$ & $<0.001$ \\
\hline $\begin{array}{l}\text { Location (left over } \\
\text { right side) }\end{array}$ & 0.39 & 1.48 & $1.40-1.56$ & $<0.001$ \\
\hline $\begin{array}{l}\text { Ultrasound (poor } \\
\text { prognosis sign) }\end{array}$ & 0.30 & 1.35 & I.29-1.42 & $<0.001$ \\
\hline $\begin{array}{l}\text { Method of reduction } \\
\text { (hydrostatic over } \\
\text { pneumatic) }\end{array}$ & 0.29 & 1.34 & $|.04-1.7|$ & 0.023 \\
\hline
\end{tabular}

Abbreviation: RR, relative risk.

Table 3 Item scoring scheme for predictors for failure reduction of intussusception derived from coefficients of selected indicators

\begin{tabular}{|c|c|c|c|}
\hline $\begin{array}{l}\text { Risk } \\
\text { indicators }\end{array}$ & Coefficients & $\begin{array}{l}\text { Transformed } \\
\text { coefficients }\end{array}$ & $\begin{array}{l}\text { Assigned } \\
\text { score }\end{array}$ \\
\hline \multicolumn{4}{|l|}{ Weight } \\
\hline$\leq 12 \mathrm{~kg}$ & 0.39 & 1.70 & 2 \\
\hline$>12 \mathrm{~kg}$ & - & - & 0 \\
\hline \multicolumn{4}{|c|}{ Duration of symptoms } \\
\hline$\leq 48$ hours & - & - & 0 \\
\hline$>48$ hours & 0.23 & 1 & I \\
\hline \multicolumn{4}{|l|}{ Vomiting } \\
\hline No & - & - & 0 \\
\hline Yes & 0.49 & 2.13 & 2 \\
\hline \multicolumn{4}{|l|}{ Rectal bleeding } \\
\hline No & - & - & 0 \\
\hline Yes & $0.4 I$ & 1.78 & 2 \\
\hline \multicolumn{4}{|c|}{ Abdominal distension } \\
\hline No & - & - & 0 \\
\hline Yes & 0.47 & 2.04 & 2 \\
\hline \multicolumn{4}{|c|}{ Temperature $>37.8^{\circ} \mathrm{C}$} \\
\hline No & - & - & 0 \\
\hline Yes & $0.4 I$ & 1.78 & 2 \\
\hline \multicolumn{4}{|l|}{ Palpable mass } \\
\hline No & - & - & 0 \\
\hline Yes & 0.23 & 1 & I \\
\hline \multicolumn{4}{|l|}{ Location } \\
\hline Right & - & - & 0 \\
\hline Left & 0.39 & 1.70 & 2 \\
\hline \multicolumn{4}{|c|}{ Ultrasound (poor prognosis sign) } \\
\hline No & - & - & 0 \\
\hline Yes & 0.30 & 1.30 & I \\
\hline \multicolumn{4}{|c|}{ Method of reduction } \\
\hline Pneumatic & - & - & 0 \\
\hline Hydrostatic & 0.29 & 1.26 & I \\
\hline
\end{tabular}

the prediction ability of the score model was $80.68 \%$ as shown in Figure 1.

The total scores were categorized into a low-risk group (scores 0-11) and a high-risk group (scores 12-16) as shown in Table 4. The majority of the failed reduction patients were in the high-risk group (94.1\%). The majority of the successful reduction patients were in the low-risk group (59.1\%). The likelihood ratio of positive showed the probability of failed reduction in each group. Patients with intussusception in the low-risk group were 0.79 times more likely to have a failed nonsurgical reduction. However, the patients in the high-risk group were 18.22 times more likely to have a failed nonsurgical reduction. Figure 2 shows a relationship between the proportion of failed reductions with the total scores. The higher the score, the increased proportion of failed reductions was shown which corresponded to the estimated risk from logistic estimation. The goodness of fit by Hosmer-Lemeshow chi-square test of this model was performed for assessing the fit of the model. There was no evidence of lack of fit $(P=0.876)$.

\section{Discussion}

Intussusception is a common disease in infants and children around the world. The method of diagnosis and management of intussusception have developed over time. Investigations for the diagnosis of intussusception have gradually changed from intraoperative diagnosis and contrast enema to ultrasonography. The management also developed from primary surgery to nonsurgical reduction if there were no contraindications. Nonsurgical reduction has also varied in the techniques. The development of hydrostatic and pneumatic reduction techniques under radiologic guidance

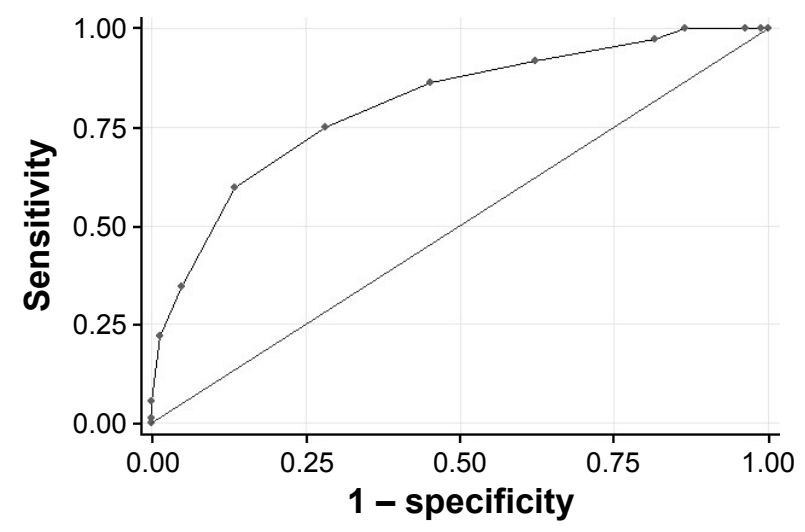

Figure I The ROC curve of failure nonoperative reduction of intussusceptions predicted by risk scoring scheme (curved line) and a $50 \%$ chance prediction (diagonal line). Notes: Area under the ROC curve $=0.8068$; $95 \%$ Confidence Interval = $0.7390-0.8762$.

Abbreviation: ROC, receiver operating characteristic. 
Table 4 Distribution of risk of failed nonoperative reduction of intussusceptions, $\mathrm{LR}+$ and $95 \% \mathrm{Cl}$ of LR+

\begin{tabular}{llllll}
\hline Risk level & $\begin{array}{l}\text { Failed, } \\
\mathbf{n}(\%)\end{array}$ & $\begin{array}{l}\text { Successful, } \\
\mathbf{n}(\%)\end{array}$ & $\begin{array}{l}\text { LR+ } \\
\end{array}$ & $\begin{array}{l}\mathbf{9 5 \% C l} \\
\text { of LR+ }\end{array}$ & P-value \\
\hline Low (score $\leq$ II) & $56(40.9)$ & 8 I (59.I) & 0.79 & $0.69-0.89$ & $<0.00$ I \\
High (score > II) & I6 (94.I) & I (5.9) & I8.22 & $2.48-134.02$ & $<0.00$ I \\
\hline
\end{tabular}

Abbreviation: LR+, likelihood ratio of positive.

(ultrasonography or fluoroscopy) has still been reported. ${ }^{10-13}$ The decision for the method of diagnosis and treatment was dependent on patient characteristics, experience of patient care team (surgeons, radiologists, and pediatricians), facilities, and equipment.

In 2013, Jiang et al $^{3}$ collected the published data of intussusception in seven geographic regions of the world. He reported that the diagnosis of intussusception was mostly found by ultrasound in Central and South America, contrast enema in Eastern Mediterranean, and surgery in Africa. For the management, primary treatment was air or barium enema except in Africa and Central and South America where surgery was the primary treatment.

In our study, nonsurgical reduction was attempted if there were no contraindications with a success rate of $55.3 \%$. We studied the prognostic indicators for failed reduction and found ten parameters in our earlier study. ${ }^{8}$ There were a few earlier reports about predictors in the literature. In 2016, Ntoulia et a ${ }^{14}$ reported that the ultrasound findings of a distal mass and observation of the dissecting sign were the predictors for failed reduction. In 2015, Wong et a ${ }^{15}$ found a palpable abdominal mass to be a risk factor. In 2014 , He et $\mathrm{al}^{6}$ found that the presence of bloody stool, free peritoneal fluid, trapped fluid in the intussusception, and location in the left side of the abdomen were associated with a lower success rate. Our study found that the predictors included the clinical signs and symptoms along with the ultrasound findings and mode of reduction.

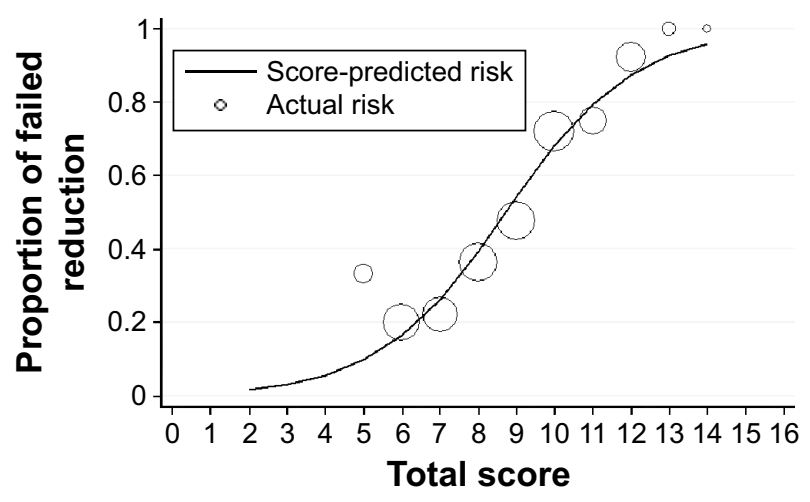

Figure 2 Score-predicted risk (line) and actual risk (circles) of failed nonsurgical reduction of intussusception for each total score.
From the earlier reviews, there were some scoring systems. In 1986, Guo et a ${ }^{16}$ reported a large series of intussusception treated with air pressure enema. In that study, he proposed a clinical criteria scoring system as a guide in the determination of initial treatment. The parameters in that scoring system were the clinical signs and symptoms. In 2011, Weihmiller et al ${ }^{17}$ set up the clinical criteria for the diagnosis of intussusception with a decision tree. His criteria, however, did not indicate a clinical prediction for failed reduction. In our study, we set up clinical prediction rules for predicting the failure of nonsurgical reduction of intussusception. We used the parameters from demography (body weight), symptoms (duration of symptoms, vomiting, rectal bleeding, and abdominal distension), signs (body temperature, palpable mass, and location of the mass), sonographic findings, and the method of reduction to calculate the scores.

The prediction of the nonsurgical reduction results might help the physician to communicate with the parents about the importance of attempting a nonsurgical reduction and prognosis of the patient. In some areas with no facilities for reduction, surgery was the treatment. The prediction scores may be used to facilitate the referral of cases to the center in which nonsurgical reduction could be performed. However, this study was a retrospective study that was one of our limitations. The validation of this prediction score should be performed before its actual use.

\section{Conclusion}

These scoring guidelines were used to predict the results of nonoperative reduction and forecast the prognosis of the failed reduction. The usefulness of these prediction scores was to inform the parents before the reduction. These scores can be used as a guide to promote the referral of the cases to tertiary centers with facilities for nonoperative reduction if possible. Nevertheless, contraindications preventing nonoperative reduction still remain such as peritonitis, free air in abdominal X-ray, and nonresponsive shock. Validation for these scores is planned for the next study.

\section{Disclosure}

The authors report no conflicts of interest in this work.

\section{References}

1. Columbani PM, Scholz S. Intussusception. In: Coran AG, Adzick NS, Krummel TM, Laberge J-M, Shamberger RC, Caldamone AA, editors. Pediatric Surgery. Vol. 2. 7th ed. USA: Saunders; 2012:1093-1110.

2. Bines JE, Ivanoff B, Justice F, Mulholland K. Clinical case definition for the diagnosis of acute intussusception. J Pediatr Gastroenterol Nutr. 2004;39(5):511-518. 
3. Jiang J, Jiang B, Parashar U, Nguyen T, Bines J, Patel MM. Childhood intussusception: a literature review. PLoS One. 2013;8(7):e68482.

4. Chalya PL, Kayange NM, Chandika AB. Childhood intussusceptions at a tertiary care hospital in northwestern Tanzania: a diagnostic and therapeutic challenge in resource-limited setting. Ital $J$ Pediatr. 2014;40(1):28.

5. Bekdash B, Marven SS, Sprigg A. Reduction of intussusception: defining a better index of successful non-operative treatment. Pediatr Radiol. 2013;43(6):649-656.

6. He N, Zhang S, Ye X, Zhu X, Zhao Z, Sui X. Risk factors associated with failed sonographically guided saline hydrostatic intussusception reduction in children. J Ultrasound Med. 2014;33(9):1669-1675.

7. Fallon SC, Lopez ME, Zhang W, et al. Risk factors for surgery in pediatric intussusception in the era of pneumatic reduction. $J$ Pediatr Surg. 2013;48(5):1032-1036.

8. Khorana J, Singhavejsakul J, Ukarapol N, Laohapensang M, Siriwongmongkol J, Patumanond J. Prognostic indicators for failed non-surgical reduction of intussusception. Ther Clin Risk Manag. 2016; 12:1231-1237.

9. Khorana J, Singhavejsakul J, Ukarapol N, Laohapensang M, Wakhanrittee J, Patumanond J. Enema reduction of intussusception: the success rate of hydrostatic and pneumatic reduction. Ther Clin Risk Manag. 2015;11:1837-1842.

10. Shehata S, El Kholi N, Sultan A, El Sahwi E. Hydrostatic reduction of intussusception: barium, air, or saline? Pediatr Surg Int. 2000;16(5-6): $380-382$.
11. Di Renzo D, Colangelo M, Lauriti G, De Girolamo F, Persico A, Lelli Chiesa P. Ultrasound-guided Hartmann's solution enema: first-choice procedure for reducing idiopathic intussusception. Radiol Med. 2012; 117(4):679-689.

12. Bai YZ, Qu RB, Wang GD, et al. Ultrasound-guided hydrostatic reduction of intussusceptions by saline enema: a review of 5218 cases in 17 years. Am J Surg. 2006;192(3):273-275.

13. Sadigh G, Zou KH, Razavi SA, Khan R, Applegate KE. Meta-analysis of air versus liquid enema for intussusception reduction in children. AJR Am J Roentgenol. 2015;205(5):W542-W549.

14. Ntoulia A, Tharakan SJ, Reid JR, Mahboubi S. Failed intussusception reduction in children: correlation between radiologic, surgical, and pathologic findings. AJR Am J Roentgenol. 2016;207(2):424-433.

15. Wong $\mathrm{CW}$, Chan IH, Chung PH, et al. Childhood intussusception: 17-year experience at a tertiary referral centre in Hong Kong. Hong Kong Med J. 2015;21(6):518-523.

16. Guo JZ, Ma XY, Zhou QH. Results of air pressure enema reduction of intussusception: 6,396 cases in 13 years. J Pediatr Surg. 1986;21(12): 1201-1203.

17. Weihmiller SN, Buonomo C, Bachur R. Risk stratification of children being evaluated for intussusception. Pediatrics. 2011;127(2): e296-e303.
Therapeutics and Clinical Risk Management

\section{Publish your work in this journal}

Therapeutics and Clinical Risk Management is an international, peerreviewed journal of clinical therapeutics and risk management, focusing on concise rapid reporting of clinical studies in all therapeutic areas, outcomes, safety, and programs for the effective, safe, and sustained use of medicines. This journal is indexed on PubMed Central, CAS,

\section{Dovepress}

EMBase, Scopus and the Elsevier Bibliographic databases. The manuscript management system is completely online and includes a very quick and fair peer-review system, which is all easy to use. Visit $\mathrm{http}: / /$ www.dovepress.com/testimonials.php to read real quotes from published authors. 